\title{
FACILE IN VITRO GLASS SLIDE LIGHT MICROSCOPY METHOD USING TETRACYCLINE TO VISUALIZE A REPETITIVE PATTERN IN AERIAL PLANT ROOT TIPS FILAMENTOUS NETWORK
}

\author{
Abrahám A. Embí BS MBA \(iD) \\ *1 13442 SW 102 Lane, Miami Florida, USA 33186
}

DOI: https://doi.org/10.29121/granthaalayah.v8.i12.2020.2699

Article Type: Research Article

Article Citation: Abrahám A. Embí BS MBA. (2020). FACILE IN VITRO GLASS SLIDE LIGHT MICROSCOPY METHOD USING TETRACYCLINE TO VISUALIZE A REPETITIVE PATTERN IN AERIAL PLANT ROOT TIPS FILAMENTOUS NETWORK. International Journal of Research GRANTHAALAYAH, 8(12), 152-166. https://doi.org/10.29121/granthaa layah.v8.i12.2020.2699

Received Date: 07 November 2020

Accepted Date: 31 December 2020

Keywords:

Tetracycline Adhesion Cellulose Orchid Air Roots Plant Cell Apoptosis Plant Cell Wall Filaments Repetitive Pattern

\section{ABSTRACT}

The main purpose of this manuscript is to introduce a facile light microscopy methodology to visualize plant roots filaments. In a previous manuscript in vitro experiments on freshly plucked human hair roots documented the commonly used antibiotic Tetracycline (TE) deleterious effect on soft tissue, severe enough to allow for visualization of an underlying filamentous skeleton. In this manuscript, TE was also evaluated in a similar fashion of in vitro experiments, this time aerial plant roots were immersed in liquid Tetracycline. Images and video recordings are presented where plant aerial root tissue cells appeared to interact with Tetracycline, thus allowing for exposure of an underlying filamentous network. These filaments were documented undergoing biosorption of Tetracycline, thus indicating a probable keratin base. It is emphasized that a literature search showed similar, albeit visually different displays of roots filaments obtained by using a Scanning Electron Microscopy. The method herein introduced could be an adjunct to existing established methodology in root function research. Two salient advantages are identified, firstly that the essential minimal material and equipment is limited to a light microscope, glass slides, chosen biological material, water and powder Tetracycline. Secondly, the speed in obtaining results would offer researchers a preliminary or perhaps a final correct conclusion.

\section{INTRODUCTION}

The deleterious effect of Tetracycline on the human hair follicle soft tissue was recently demonstrated in vitro [1]. In that paper, in toto human hairs were immersed in drops of diluted powder of a commonly used antibiotic, namely Tetracycline (TE). The adhesive property of TE was proposed as one factor in damaging the human follicle's metabolism, as well as a myriad of soft tissue cells. Images of the follicle's keratin architecture were displayed (Fig 1).

The present manuscript introduces a deleterious effect of liquid TE to aerial plant root tip tissue. Fresh harvested orchid hanging aerial root tips were exposed to liquid TE by via a previously describe technique dubbed a Single Slide Preparation (SSP) [2]. The images obtained show a damaging effect of TE on external root epidermal and internal trichoblats cells, also documented are detailed images of a continuous filamentous veil seen covering the interior tissue. The outer epidermal cells failed to exhibit a filamentous covering network.

(C) 2020 The Author(s). This is an open access article distributed under the terms of the Creative Commons Attribution License, which permits unrestricted use, distribution, and reproduction in any medium, provided the original author and source are credited. 


\section{MATERIALS AND METHODS}

\section{Materials}

1) Freshly harvested orchids aerial root tips.

2) Tetracycline $500 \mathrm{mg}$ capsules.

3) Medicine Dropper.

4) Microscope glass slides: $25 \times 75 \times 1 \mathrm{~mm}$ thickness. Pearl Cat. No. 7101

5) Digital Video Microscope Celestron II model \# 44341, California, USA.

6) Images downloaded to an Apple Computer MacBook Pro Photo Application.

\section{Methods}

Tetracycline capsules (500 mg) were pierced at one end and the golden yellow powder transferred to a clean white glass plate. The power was divided by a double edge razor blade into 10 piles each estimated to contain 100 $\mathrm{mg} /$ pile. The subdivision progressed until piles of estimated $5 \mathrm{mgs}$ each were reached (Exhibit I below).

\section{EXHBIT I}

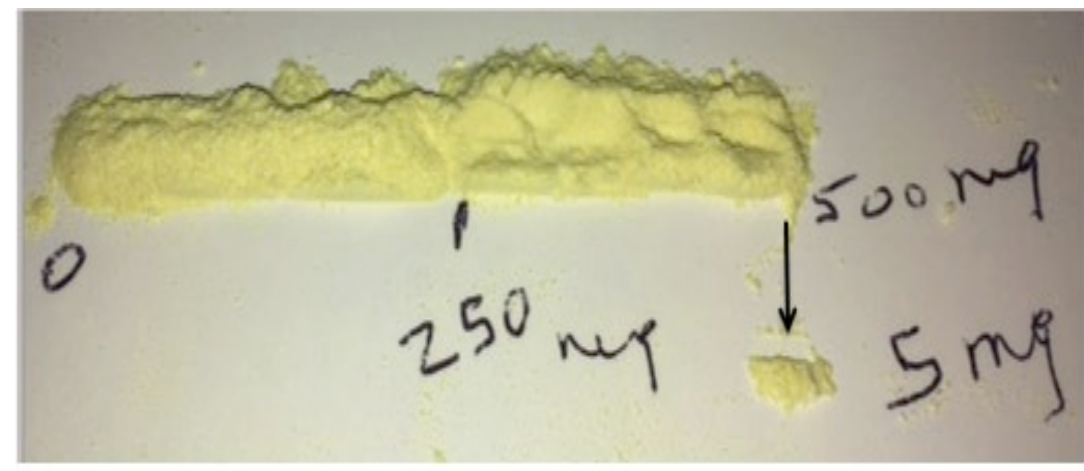

Yellow Golden Powder from Pierced $500 \mathrm{mg}$ Tetracycline Capsule

Black Arrow: Estimated $5 \mathrm{mg}$ used for in vitro experiments

\section{THE LIQUID TETRACYCLINE}

On a separate glass slide approximate a very small amount of TE powder, such as the minimal amount adhering to a toothpick was placed on the slide. Using a medicine dropper three small demineralized drinking bottle water drops were delivered and the powder stirred for a few seconds. For the purpose of the experiments, this aqueous solution was dubbed "liquid Tetracycline" (LT).

\section{THE ROOT TISSUE IMMERSION IN LIQUID TETRACYCLINE}

Freshly harvested orchids areal root tips were placed on a glass slide. A sharp blade was used to perform a longitudinal thin cut of the distal end as shown in Figure 1 below. 


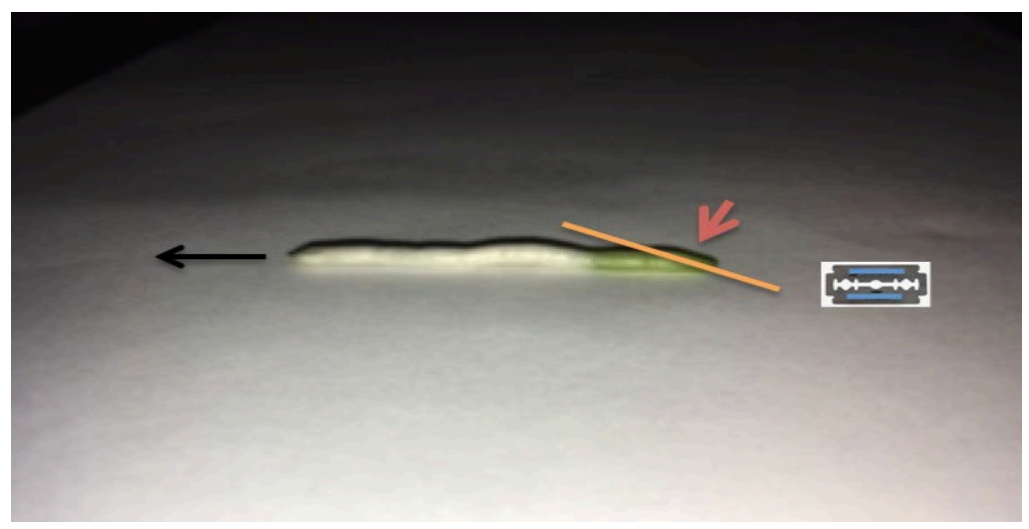

Figure 1: Freshly harvested Orchid aerial root tip. Black Arrow: Harvest cut to plant. Red Arrow: Distal aerial end thin segment for experiment. Orange Line: Delineating approximate longitudinal thin cut by sharp razor blade.

Using small tweezers, the previously thin distal aerial root cut sample was placed in the LT. The LT drops were gently dispersed on the slide, this in order to stabilize root tissue drift towards the drop's edges. Once stabilized, the preparation was placed on the optical video-microscope platform, and allowed to dry. Control images and video recordings after LT evaporation recorded and saved for downloading into a McBrook Apple Computer photo application.

\section{RESULTS}

To show the results of the effect of LT on plant root tissue, we need to refer the reader to an image showing the effect of LT in human soft tissue tissue of the human hair follicle a.k.a. root (1) and Figure 2 below.

\subsection{HUMAN HAIR FOLLICLE TISSUE IMBEDDED IN LIQUID TETRACYCLINE}

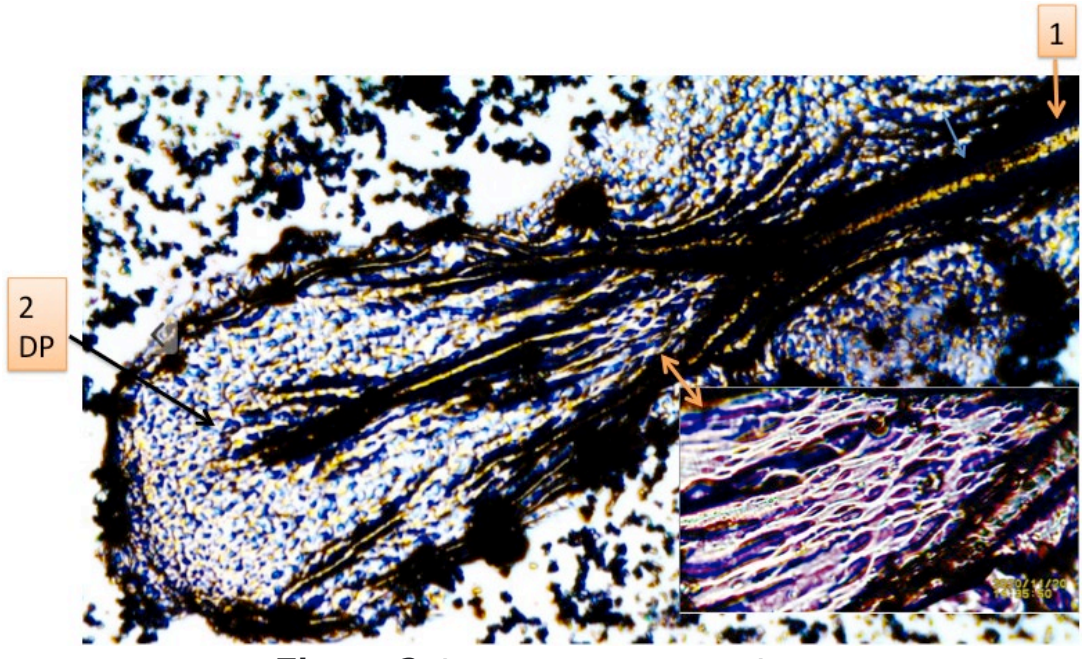

Figure 2: in present manuscript.

Liquid showing stained golden yellow Tetracycline adhered to hair follicle filaments skeleton. Notice damage to soft tissue of Dermal Papilla (DP). Also, as primary starting point for hair follicle inner keratinized filaments. Orange arrow showing: 1 (right upper corner) Keratin adhesion to keratin-based hair shaft cuticles, Orange Double Arrow: Denoting amplified area of typical complex filamentous nature.

Original image reproduced from: Embi AA. (2020) THE HUMAN HAIR FOLLICLE AS SENTINEL FOR DRUGS EVALUATION: DEMONSTRATION OF TETRACYCLINE ADHESION TO HAIR FOLLICLE AS PROPOSED MECHANISM IN DYSFUNCTIONAL HAIR LOSS. In Print IJRG December 2020. 


\subsection{PLANT AERIAL ROOTS TISSUE CONTROL}

In the case of distal aerial plant tissue, the results obtained are comparatively close to its animal counterpart. Control images of root tip cells immersed in plain water drops show a thick cell wall and different filament orientation within each trichoblast cell (Figure 2)

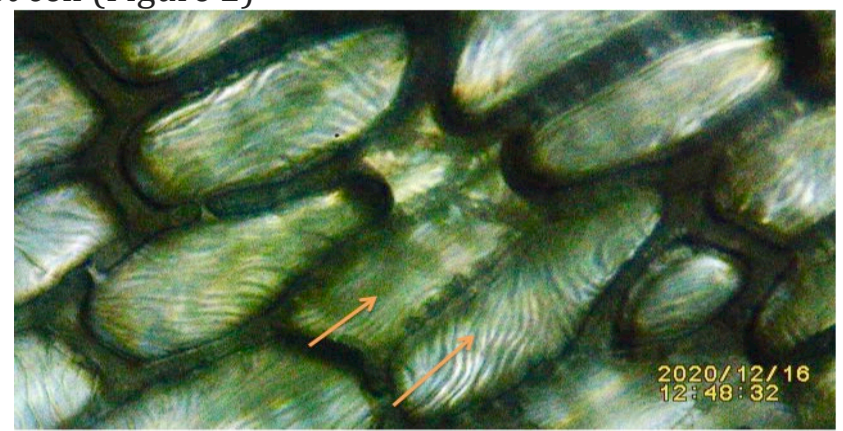

Figure 2: Control orchid aerial root thin cut sample immersed in plain demineralized water showing: Orange Arrows: Different individual patterns of intracellular filaments orientation in trichoblast cells.

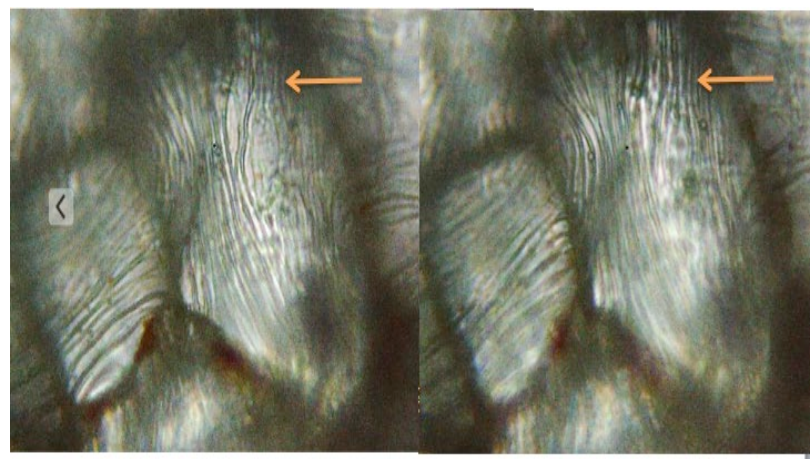

Figure 3: Same orchid aerial root tip cells shown side by side in liquid tetracycline, after evaporation, showing: Orange Arrows: Root tissue filament network, as microscope depth of field changes additional filaments appeared; demonstrating a layering effect between cells. The cell walls appeared thinner.

\subsection{PLANT AERIAL TISSUE IMBEDDED IN LIQUID TETRACYCLINE}

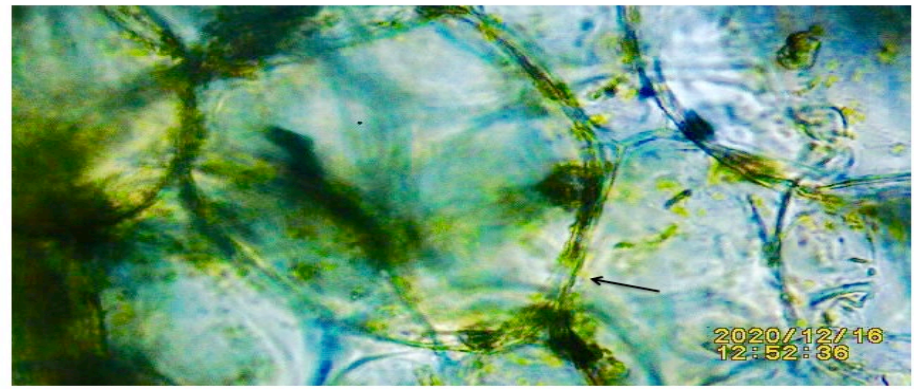

Figure 4: Epidermal cell post three minutes immersion in Tetracycline. Black Arrow: Pointing at epidermal cell wall already showing TE biosorption. Notice the absence of a filamentous network, since these are external root cells.

For further details documenting tissue cells layers please link to URL https://youtu.be/XHsGmWoFpLc Or Scan QR Code in upper left corner of image. 


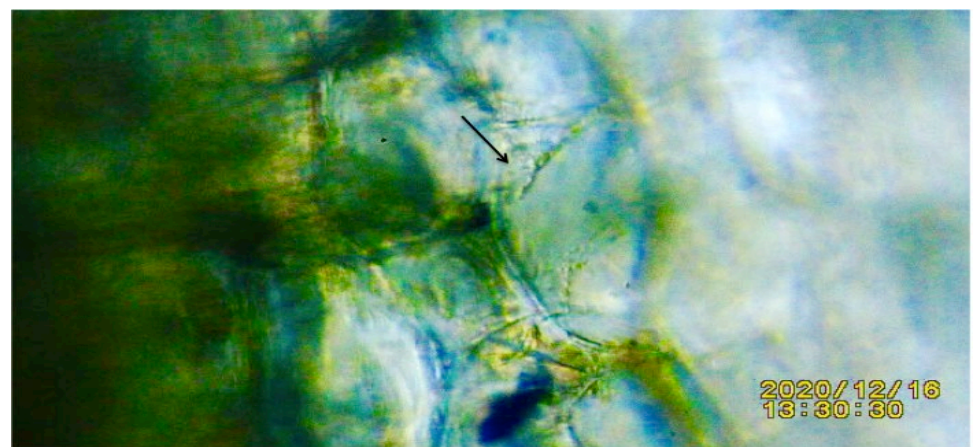

Figure 5: Same epidermal as in Figure 4 above, now 38 minutes post immersion in liquid Tetracycline showing: Black Arrow: Extensive cell wall damage indicating apoptosis.

\subsection{INTRODUCING REPETITIVE PATTERN FILAMENTOUS NETWORK OF AERIAL ROOTS}

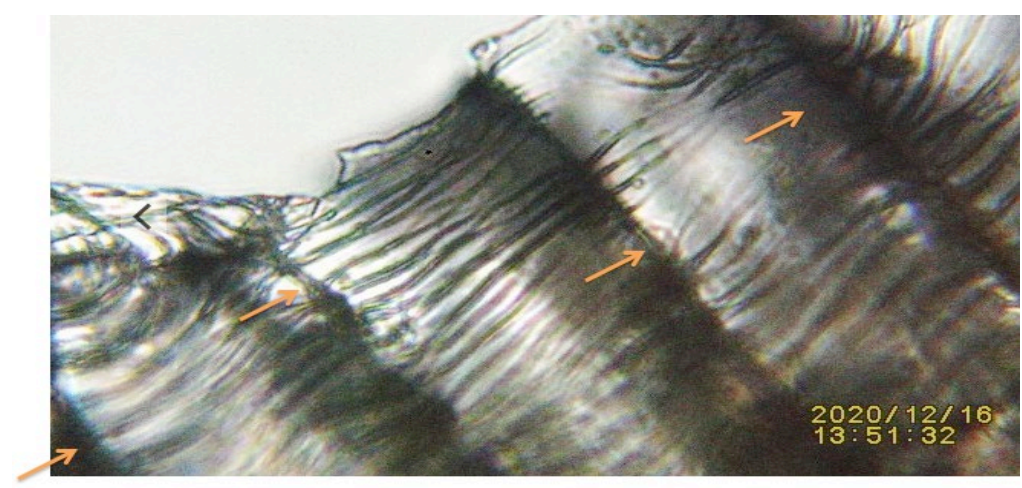

Figure 6: Orchid Aerial root cut end amplified. Orange Arrows supporting a filamentous repetitive pattern.

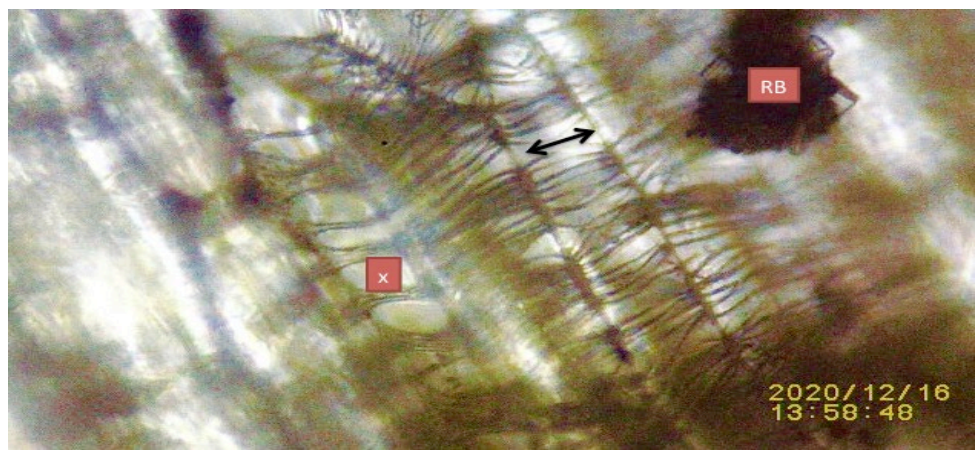

Figure 7: Image showing complex filaments displayed by aerial orchid root tip cells. X: Unidentified filamentous structure. RB: Raphide bundle. Double Head Black Arrow: Pointing at laterally communicating filament structures.

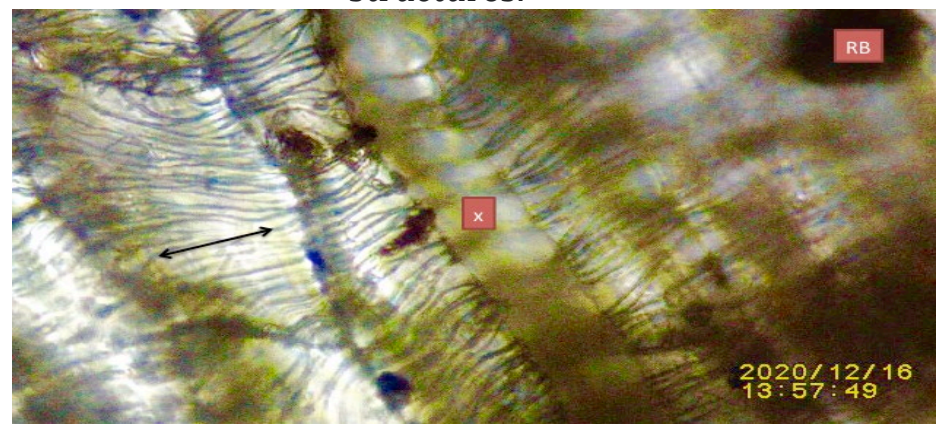

Figure 8: Same area as Figure 7 above. Using landmarks as the raphide bundle (RB) and the unidentified filamentous structure $(\mathrm{x})$, the observer could appreciate a filamentous repetitive pattern as demonstrated in Figure 6. 


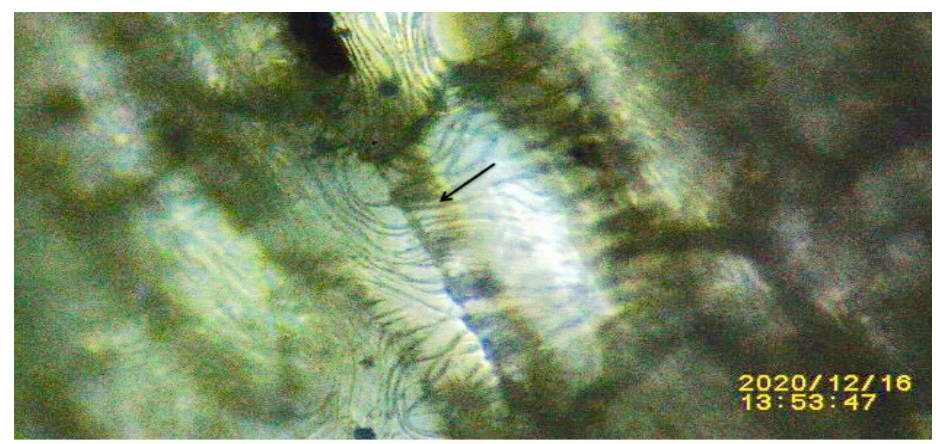

Figure 9: Black Arrow: Showing filaments also covering structures such as xylem vessels

\section{DISCUSSION}

In this manuscript, in vitro experiments done on aerial plant root tissue introduces a facile method utilizing a commonly used antibiotic (Tetracycline) in aqueous form in direct contact with aerial plant root tissue able to uncover details of an intercellular filamentous veil. Of relevancy, also documented for the first time repetitive growth pattern of filamentous network in aerial plant roots (Figures 3,6,7,8,9).

A literature search failed to show the aforementioned repetitive filamentous pattern in plant roots as shown in these experiments; instead, a paper was found and it behooves corroboration by institutional affiliated researchers with a greater access to published data.

The Two Faces of Repetition

Periodicity and the described phenomena of repetitive motion of DNA parts in cell division could induce or stunt growth of cellular structures, and could occur at many levels during tissue growth formation in both plants and animal tissue [3], [4]. On the other hand, a repetitive protein is essential for filament structure and function in parasites [5]. Since the antibiotic Tetracycline and its derivatives have also been reported to impact on the physiology and biochemistry in tissues of plants and animals [6], it could be stated that it has a deleterious impact on plant and animal cells, to the point of sort of eliminating barriers in light microscopy fields, thus allowing for the visualization of the repetitive patterns herein introduced (Figs 4,5 plus video recording) supporting this principle.

\section{SUMMARY AND CONCLUSSIONS}

\section{I leave you with words from a renowned biologist}

"Orchids of many kinds have also adopted this high life. They lack the ponds that sustain the bromeliads, so they must collect their nourishment in other ways. Some dangle their roots in the air, absorbing moisture from the humid atmosphere and rely on the tiny number of nutriments it might have dissolved on its descent through the forest vegetation. Others spread their roots over the surface of the branches and collect the water that has trickled through the leaves and dripped from branch to branch, gathering a little nutriment on the way." [7], [8]

Keratin as part of Aerial Root Filaments

Regardless of the physics behind light microscopy imaging, the fact remains that the antibiotic Tetracycline when in contact with aerial plant roots appears to adhere albeit sparing root filaments from damage (Figure 10). This finding is in support of an additional substance such as keratin as part of the root tip filament base [9], plus LT has been previously documented adhering to keratin in human hair follicle filaments (Figure 2); furthermore in vitro experiments have documented "the explicit features of plant keratin intermediate filaments is a 24-25 nm periodic structural repeat alone the axis of both the $10 \mathrm{~nm}$ filaments and protofilarnents" [10]. The function of the repetitive filamentous network is theorized to be of physical support to roots inner tissue.

Plant Cell Walls and Liquid Tetracycline

Aerial plant root tip epidermal cells walls are dissolved, thus pointing towards a cellulose base. 
The facile method herein introduced could facilitate root function researchers in obtaining a rapid preliminary display of supporting root tissue filaments. The novel facile rapid method herein introduced could be used to obtain preliminary; or perhaps final images of plants and human hair roots filamentous anatomy.

Tetracycline Adhesion to Root Filaments

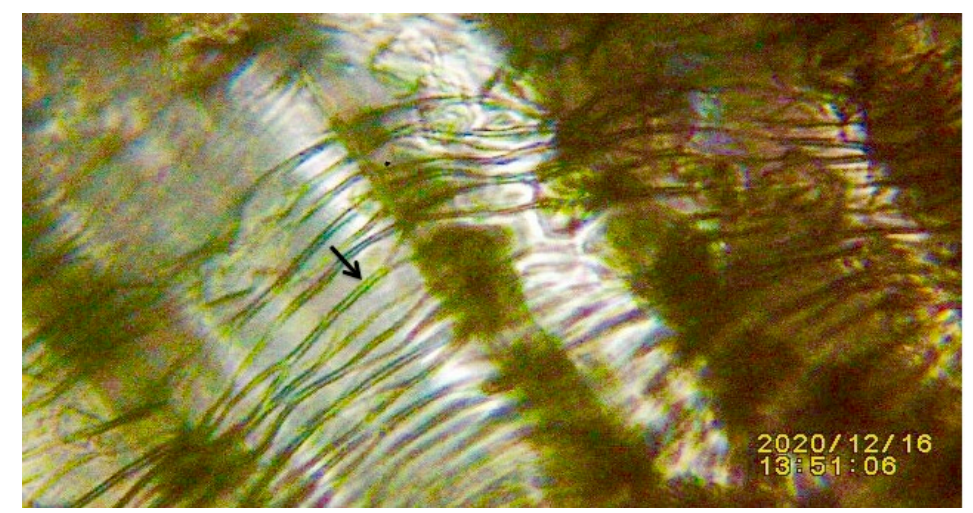

Figure 10: Orchid aerial root post immersion in liquid Tetracycline. Black Arrow: Pointing at yellow golden Tetracycline seen on filament supporting a keratin base. Please compare with Figure 2 showing Tetracycline adhesion to keratin in human hair filaments.

\section{SOURCES OF FUNDING}

This research received no specific grant from any funding agency in the public, commercial, or not-for-profit sectors.

\section{CONFLICT OF INTEREST}

The author have declared that no competing interests exist.

\section{ACKNOWLEDGMENT}

None.

\section{REFERENCES}

[1] Embi AA. (2020) THE HUMAN HAIR FOLLICLE AS SENTINEL FOR DRUGS EVALUATION: DEMONSTRATION OF TETRACYCLINE ADHESION TO HAIR FOLLICLE AS PROPOSED MECHANISM IN DYSFUNCTIONAL HAIR LOSS. IJRG 8(11), 324-332. https://doi.org/10.29121/granthaalayah.v8.i11.2020.2521

[2] Scherlag BJ, Sahoo K, Embi AA. Novel and Simplified Method for Imaging the Electromagnetic Energy in Plant and Animal Tissue. Journal of Nanoscience and Nanoengineering. 2016 Vol 2 No 1, pp 6-9

[3] Qiu, Y., Antony, E., Doganay, S., Koh, H. R., Lohman, T. M., \& Myong, S. (2013). Srs2 prevents Rad51 filament formation by repetitive motion on DNA. Nature communications, 4, 2281. https://doi.org/10.1038/ncomms3281

[4] Kim, Y.W., Moon, H.K. \& Son, S.C. Repetitive somatic embryogenesis and plant regeneration in Zizyphus jujuba Mill. In Vitro Cell.Dev.Biol.-Plant 42, 247-251 (2006). https://doi.org/10.1079/IVP2006754

[5] Vaughan S, Kohl L, Ngai I, Wheeler RJ, Gull K. A repetitive protein essential for the flagellum attachment zone filament structure and function in Trypanosoma brucei. Protist. 2008 Jan;159(1):127-36. doi: 10.1016/j.protis.2007.08.005. Epub 2007 Oct 22. PMID: 17945531. 
Facile In Vitro Glass Slide Light Microscopy Method Using Tetracycline to Visualize A Repetitive Pattern in Aerial Plant Root Tips Filamentous Network

[6] Margas M, Piotrowicz-Cieślak AI, Michalczyk DJ, Głowacka K. A Strong Impact of Soil Tetracycline on Physiology and Biochemistry of Pea Seedlings. Scientifica (Cairo). 2019 Jan 10; 2019:3164706. doi: 10.1155/2019/3164706. PMID: 30733888; PMCID: PMC6348853.

[7] David Attenborough (1995:166) The Private Life of Plants. BBC Books

[8] Zotz G, Winkler U (2013) Aerial roots of epiphytic orchids: the velamen radicum and its role in water and nutrient uptake. Oecologia, 171(3): 733-741

[9] Manali Rathod, Soumya Haldar, Shaik Basha. (2015) Nanocrystalline cellulose for removal of tetracycline hydrochloride from water via biosorption: Equilibrium, kinetic and thermodynamic studies Ecological Engineering 84:240-249

DOI: $10.1016 /$ j.ecoleng.2015.09.031

[10] Min, G., Yang, C., Tong, X., \& Zhai, Z. (2008). Assembly characteristics of plant keratin intermediate filaments in vitro. Science in China Series C: Life Sciences, 42, 485-493.

DOI:10.1007/BF02881772

Corpus ID: 13003144 . 